\title{
EL ARTE COMO INVESTIGACIÓN
}

\section{Jaime Cerón Silva}

Magíster en Estudios Culturales

Maestro en Artes

Asesor de Artes del Ministerio

de Cultura de Colombia

jceron@mincultura.gov.co

Conferencia

Recibido: 17 de abril de 2012

Aceptado: 3 de octubre de 2012
"Si el placer de la interpretación modernista consiste en el efecto del reconocimiento que "educa y refina"

el carácter inquietante de su objeto [...] la meta del tratamiento posmodernista es separarlo de su carácter familiar"

(Zizek, 1994, p. 8)

Dentro del célebre libro Todo lo que usted siempre quiso saber sobre Lacan y nunca se atrevió a preguntarle a Hitchcock, Slavoj Zizek se pregunta acerca de las transformaciones que involucra la noción de interpretación en el paso del modernismo al posmodernismo. Si ambos períodos parten de concebir un objeto como inseparable de su interpretación, en el primer caso ésta nos llevará a una familiarización con el carácter inquietante de su objeto, mientras que en el segundo a una separación de cualquier posible familiaridad frente a él. Ante la más simple estructura, por digerible y banal que parezca, el posmodernismo siempre encontrará un hecho siniestro, que encierre algo inquietante, extraño o misterioso. Una especie de retorno de lo reprimido.

Eso fue precisamente lo que ocurrió dentro de las discusiones e investigaciones teóricas generadas después del modernismo frente al concepto de autonomía del arte. Desde el punto de vista político, resulta altamente provechoso para las esferas sociales dominantes, el planteamiento de un mundo cuya sustancia fundamental no esté 
disponible a la experiencia, porque la única manera de saber de ella sería mediantelas convenciones culturales latentes en los discursos hegemónicos, que imprimen desde el comienzo su sesgo de interpretación respecto a lo real. Por ese motivo, pocas aseveraciones están tan políticamente cargadas como afirmar que el arte imita la naturaleza; o proponer que el arte surge del interior del sujeto que lo crea; o señalar que el arte es autónomo como actividad social. Todas estas representaciones dependen de una concepción prefigurada del mundo que privilegia el orden privado anterior a la experiencia.

Por este motivo, tanto el arte "ilusionista" (conocido coloquialmente como "realismo") como el arte de carácter expresivo, deberían señalarse bajo la categoría de arte narrativo, dado que lo narrado es esa concepción de mundo que los prefigura (Krauss, 2002, pp. 19-29). A pesar de que la autonomía del arte fuera proclamada a los cuatro vientos por los más diversos protagonistas del arte moderno - a través de las sucesivas vanguardias-, solo bastó con que el modernismo pareciera haber llegado a su final, para que se relevara como la más oscura de las fantasías.

Freud decía que la fantasía funciona en tres dimensiones temporales, porque su contexto — es decir sus elementos materiales-, provienen del presente, pero el deseo que la origina surge del pasado — en las experiencias tempranas-; mientras que es en el futuro donde podría realizarse. La fantasía entonces, se produce a través de actos a la vez conscientes e inconscientes mediante los cuales la subjetividad se contrapone al campo social $^{1}$.

Unos de los rasgos característicos del arte producido posteriormente al modernismo es la constante tensión no solo sobre sus componentes convencionales (como la ilusión de profundidad o la frontalidad, en el caso de la pintura) sino principalmente sobre sus trasfondos institucionales. Cuando se hace mención a la categoría de institución dentro del campo artístico, no sólo se alude a las entidades que confinan el arte como

1 Las ideas planteadas por Freud respecto a la fantasía dentro de su artículo El poeta y los sueños diurnos, son retomadas por Linda Kauffman en su libro Malas y perversos, fantasías en la cultura y el arte contemporáneos (2000), en particular en el capítulo 1 'Exhibicionistas en el arte contemporáneo'. El interés de esta autora radica en conectar el performance, la fotografía y la narrativa de ficción desde la noción de fantasía planteada por el psicoanálisis, tanto de Freud como de Lacan. 
los museos, galerías o salas de exposición (o cualquier otro estamento) sino a los fundamentos epistemológicos en donde se sustenta la idea de arte, tales como "el artista" o "la obra", entre otros. Por eso una de las opciones que ha florecido con más vigor durante los últimos cuarenta años es la proposición de estrategias o dispositivos transdiciplinares que transfieran a la experiencia de los espectadores el enfoque crítico sobre las instituciones artísticas. Por eso muchas de estas obras parecen desafíos a los argumentos de críticos modernistas como Michael Fried quien generó cuestionamientos sobre el arte que proponía algún tipo de experiencia contingente, ya fuera asociada al cuerpo, al espacio físico o al tiempo real, al considerar que se alejaban de lo puramente visual y autónomo del arte moderno. Fried (2001) consideraba que las artes existían en sus esferas autónomas cuando afirmaban su naturaleza intrínseca y que lo que gravitaba entre ellas era el teatro, término que usaba para hacer referencia a la objetualidad, materialidad y temporalidad expandida dentro del arte. Ese sería el rasgo reprimido que retorna, como mencionaba Zizek.

Esta vocación transdisciplinar del arte posterior al modernismo se puede rastrear por sus negociaciones con las experiencias culturales provenientes de las márgenes externas a los referentes hegemónicos de la "alta cultura" y que han sido caracterizadas mediante el uso del término kitsch. El empleo de esta categoría dentro del campo artístico, ha suscitado un amplio debate académico, dado que su uso originario era peyorativo (de hecho significaba "basura cultural"). Norbert Elías, en su célebre texto de 1936, Estilo "kitsch" y época "kitsch", dejaba notar cómo este término llegaría a aludir a las prácticas culturales de la burguesía, mediadas por los efectos de la Revolución Industrial y que actuaban como reemplazo de la refinada cultura aristocrática. Si se siguen rigurosamente los argumentos planteados por Elías, podría deducirse que la totalidad del arte moderno, enteramente atado a la cultura burguesa y claramente estructurado a partir de los cambios sociales y culturales que trajo consigo la Revolución Industrial, podría fácilmente ser considerado como kitsch (Elías, 1998, pp. 72-76). En otros discursos, el kitsch se fue identificando paulatinamente con las expresiones culturares subalternas, cobijando indistintamente la cultura popular tradicional (como las artesanías) y la cultura popular masiva (como la televisión), con muchas cosas que habría entre estas dos. A partir de las concepciones artísticas de carácter posmoderno, el término se ha vuelto emblemático de las disputas simbólicas sobre la legitimidad cultural, lo que hace que funcione efectivamente para nombrar 
las prácticas culturales que ocurren por fuera de las representaciones legitimadas dentro del mundo hegemónico (Mosquera, 1989, pp. 27-31).

A partir de la década de los sesenta, no solo se ha confrontado la existencia de las disciplinas modernas sino que se han entremezclado las distintas dimensiones del campo artístico dentro de un proyecto artístico dado. Si la modernidad comprendía el contexto en que el arte se inscribe públicamente como un circuito, determinado por el paso lineal de la creación a la exhibición y al consumo (ya fuera entendido como apreciación o coleccionismo), la perspectiva contemporánea lo planea como un campo, articulado por un cruce sistemático entre sus distintas dimensiones, denominadas creación, circulación, investigación, formación y apropiación cultural (Instituto Distrital de Cultura y Turismo, 2005, pp. 35-41).

En este campo de las prácticas artísticas contemporáneas, no es posible separar un proceso creativo de su puesta en escena pública, o de una actividad de investigación de sus componentes creativos o de circulación y así de forma sucesiva. Por eso es posible generar un proyecto artístico que surja de la articulación entre procesos de investigación científica y tecnológica, que no tenga ninguna intencionalidad asociada a la normalización propia de esos campos, sino que al contrario ponga en cuestión sus categorías previas y que, adicionalmente, impida disociar sus componentes de creación, circulación y, por supuesto, de investigación. Como ejemplo podría citarse el proyecto "Cloaca" de Win Delvoye, una intrincada máquina diseñada para reproducir con la mayor fidelidad posible el efecto que produce el sistema digestivo humano sobre la comida, que hacía que su razón de ser no fuera otra cosa que ser alimentada un día, para defecar al día siguiente. Por consiguiente, la unión de los tres paradigmas emblemáticos del saber moderno —el arte, la ciencia y la tecnología- producían tan solo excrementos.

Durante las últimas cuatro décadas la misma instancia de creación en los proyectos artísticos se ha vuelto paradójica por la recurrencia a metodologías de apropiación, como ocurre en el ejemplo anteriormente citado. Este tipo de prácticas se afilian a la lógica vanguardista del readymade duchampiano, que problematizó de manera general la creencia imaginaría en la originalidad del arte, del artista y de la obra por parte de los teóricos del arte moderno. Por lo tanto no sólo cuestiona las nociones de obra y autor sino que incorpora la serialidad como principio creativo. 
"Otro aspecto del ready-made es que no tiene nada de único. La réplica de un ready-made transmite el mismo "mensaje"; de hecho casi todos los ready-mades que hoy existen no son originales en el sentido usual del término” (Duchamp, 1978).

La apropiación como táctica posmoderna implicó no solo los cuestionamientos ya formulados por Duchamp a los elementos convencionales e institucionales del arte, sino que movilizó una revisión más profunda de las representaciones culturales y políticas que el arte moviliza.

[...] el objeto calmadamente escultórico de la mirada no mira hacia el observador, y el intercambio entre los dos sujetos —uno dentro, otro fuera de la imagen - es coreografiado en cambio a través del medio del lenguaje. Es a lo largo de este eje entre los pronombres de primera y segunda persona — yo/tú — que Kruger traza el marco presuposicional para esa misma institución que llamamos subjetividad. [...]. Los sujetos (aquellos que dicen “yo”), son por lo tanto construidos, no innatos. Y son construidos en el contexto de varias instituciones en las cuales es jugado el juego del lenguaje. El arte es una de esas instituciones; pero otra, a la que Kruger añade la del arte, es la mucho más moderna de la publicidad. Pues la imagen de Kruger, combinando la fotografía con el resumido y punzante lenguaje de su texto, habla con la franqueza y la familiaridad de la voz del agente publicitario: fuerte pero seductor al mismo tiempo. La subjetividad es producida a lo largo de un eje en el cual uno de los polos es ocupado no por un locutor humano sino por una mercancía: un ayudante de belleza, un utensilio casero, un alimento del desayuno. La publicidad se ventrilocuiza a través del producto. Dice "cómprame", "ámame", "cómeme". Y el sujeto que está localizado a lo largo del eje de esta relación, entre "tú" y "yo" (la escultura fotografiada en la obra y el observador parado enfrente de ella), es construido a lo largo de las líneas de lo inorgánico, la condición sin vida de la mercancía que, sin embargo, es llamado a desear" (Krauss, 2002).

La investigación y análisis de los componentes culturales de la visión emergió como una constante dentro de muchos proyectos artísticos, porque la visión, es necesario apuntar, ha sido sinónima tradicionalmente de la mirada. Convencionalmente el campo escópico o la visualidad (definida por el deseo de ver) es el lugar donde se ha ubicado la actividad artística, de ahí que siempre que intentemos profundizar nuestro conocimiento de esta actividad nos tropecemos con la estética, que lamentablemente 
parece reducir esta situación simplemente a una experiencia sensible, que desconoce su pulsión implícita.

Vale la pena recordar, como lo hizo Maurice de Merleau Ponty, en Lo visible y lo invisible, que nuestra corporeidad nos hace objetos a la vista del mundo. Mientras miramos las cosas somos mirados por ellas. La percepción visual unida al cuerpo es parcial por lo que está en perspectiva. Jacques Lacan dice que vemos desde un solo punto de vista pero que en nuestra existencia somos mirados desde todos lados. Entonces si la mirada preexiste al sujeto, lo muestra en el campo visual como constituido por el deseo de otro. El deseo está estructurado por una pérdida y esa pérdida irrumpe en el campo visual, en la forma de la mirada, desorganizándolo (Lacan, 1997, pp. 108-110). La mirada es como una mancha que fuerza la opacidad y negatividad de lo que es tanto el objeto, como la causa de la pulsión escópica, que posee componentes culturales.

La visión consciente, ubica el ojo en el punto geometral desde el que se percibe una imagen correlativa a un objeto. Pero el inconsciente también ve, arroja sobre el sujeto una maraña de deseos, fantasías, traumas, fobias y temores. La mirada está afuera e inscribe al sujeto dentro de un cuadro o imagen, pero lo configura como una sombra o una mancha, es decir anamórficamente alterado. Si la filosofía clásica afirmó que "el sujeto es el que mira", el psicoanálisis lacaniano señalará que "el sujeto es el que es mirado". La mirada está del lado de los objetos. Sin embargo la mirada se proyectará sobre la pantalla de representaciones culturales que configuran el universo de la visualidad. Como señala Norman Bryson, la visualidad es el conjunto de concepciones y representaciones culturales que estructuran el campo de la visión que, a diferencia de la visión empírica, nos trae a colación los trasfondos perceptivos que unen el acto de ver a la experiencia subjetiva. La visualidad se basa en las construcciones históricas que sustentan simbólicamente la valoración de la visión empírica (Brysson, 1988, pp. 87-94). Por eso, se puede señalar que la visualidad es el reconocimiento de los componentes sociales de la experiencia visual tanto como de los componentes visuales del campo social.

La película Manhunt basada en la novela Dragón Rojo, está centrada en un policía que intenta detener a un asesino serial y múltiple que aniquila familias completas. El detective estudia detalladamente las bizarras características de cada escena del crimen y como parte de las evidencias analiza cuidadosamente, una y otra vez, las películas caseras que muestran 
las vidas de las familias asesinadas. Un detalle del último homicidio llama su atención; el asesino utilizó una herramienta inapropiada, excesiva, para forzar su entrada a la casa. Una pesquisa sencilla le muestra que esa puerta había sido cambiada hacía poco tiempo. Al examinar la película familiar descubre que en ella aparece una puerta más sólida, es decir, la puerta anterior. Ata cabos al ver que en todos los homicidios hay películas y descubre que al ser de carácter privado, la única oportunidad de verlas sería en el laboratorio de revelado y soluciona el caso con esta información. Zizek llama la atención sobre la manera como la resolución de este caso implica la coincidencia de la mirada del policía con la mirada del asesino. Sólo cuando el policía se identifica con la perversión obsesiva del asesino y actúa como él puede encontrar las pistas finales, como es el hecho de darse cuenta de que en cada crimen hay películas para ver. Frente a una situación sádico-perversa la única solución es emplear un procedimiento sádico-perverso que se produce en la coincidencia de las dos miradas.

La anterior historia nos recuerda que cuando vemos un objeto, éste está mirándonos de antemano, desde un punto que no podemos ver. Esta imposibilidad de coincidencia recuerda la parábola lacaniana según la cual ante el objeto del deseo los sujetos son demasiado rápidos o demasiado lentos.

Esta dimensión de la mirada como objeto está presente en un proyecto artístico como Pasado tiempo futuro de Nicolás Consuegra, básicamente por su recurrencia en plantear la realidad latente, dentro de las fotografías, como aquello que gira en torno a una "mancha" o una "cosa siniestra". La tarjeta de invitación para el evento inaugural de este proyecto era una fotografía de un interior bogotano realizada en blanco y negro por el fotógrafo alemán Paul Beer en 1962. La muestra estaba conformada por diferentes pares de fotografías que parecen iguales a simple vista, pero que al ser miradas con atención dejaban ver la existencia de una serie de sutiles diferencias entre ambas. Entre todos estos pares de imágenes, se destacaba la misma imagen de la invitación porque no tenía doble fotográfico, sino que contaba con un modelo tridimensional a escala real, del espacio arquitectónico que en ella se veía, que estaba construido al otro lado de la sala. Este modelo tridimensional estaba enteramente realizado en blanco y negro y al mirar nuevamente la fotografía anterior se hacia evidente que no era la imagen "original" de Paul Beer sino el registro de la instalación que Consuegra había construido in situ, que además estaba fotografiada a colores, aunque no lo revelara en apariencia. El ejercicio de mirar insistentemente las diferencias tendía a 
centrar la mirada de los espectadores, pero el encuentro anómalo con el par de imágenes formado por la instalación y su doble fotográfica la descentraba. Esta constatación cubría de extrañeza todas las demás imágenes que podrían parecer registros de una realidad inexistente, que volvía siniestra la presencia de la arquitectura misma en que el espectador se encontraba parado, por el efectivo juego de lo reprimido que retorna. En la reconstrucción arquitectónica de una fotografía moderna hay algo fuera de lugar. La mirada fija o petrificada de un espacio puede ser una estrategia para anunciar la presencia de ese "algo", como el sustituto del campo convencional que emerge dentro de la visualidad.

\section{Referencias}

Bryson, N. (1988). 'The Gaze in the Expanded Field'. Hal Foster (ed.). Vision and Visuality. Cambridge: Seattle, Bay press.

Duchamp, M. (1978). Gili, G. (ed.). Escritos Duchamp du Signe, Colecc. Barcelona: Comunicación Visual Ed.

Elías, N. (1998). "Estilo 'kitsch' y época 'kitsch"”. Weiler, V. (comp.). La civilización de los padres y otros ensayos. Bogotá: Norma.

Fried, M. (2004). 'Arte y objetualidad'. K. Madrid: Editorial la Balsa de la Medusa.

Instituto Distrital de Cultura y Turismo (2005). Políticas culturales distritales 2004-2016, Bogotá: Alcaldía Mayor de Bogotá - Instituto Distrital de Cultura y Turismo.

Kauffman, L. (2000). Malas y perversos, fantasías en la cultura y el arte contemporáneos. Madrid: Frónesis.

Krauss, R. (2002). 'Tiempo narrativo: el problema de las puertas del infierno'. Pasajes a la escultura moderna. Madrid: Akal.

Lacan, J. (1997). 'La línea y la luz'. Seminario 11. Los cuatro conceptos fundamentales del psicoanálisis. Buenos Aires: Paidós

Mosquera, G. (1989). 'La balcanización de la cultura occidental'. El diseño se definió en octubre. La Habana: Arte y Literatura.

Zizek, S. (1994). 'Alfred Hitchcock, o la forma y su mediación histórica'. Todo lo que usted siempre quiso saber sobre Lacan y nunca se atrevió a preguntarle a Hitchcock. Buenos Aires: Editorial Manantial. 